NASA/TM-2013-217902

\title{
Limitations of Phased Array Beamforming in Open Rotor Noise Source Imaging
}

Csaba Horvath, Edmane Envia, and Gary G. Podboy

Glenn Research Center, Cleveland, Ohio 


\section{NASA STI Program . . . in Profile}

Since its founding, NASA has been dedicated to the advancement of aeronautics and space science. The NASA Scientific and Technical Information (STI) program plays a key part in helping NASA maintain this important role.

The NASA STI Program operates under the auspices of the Agency Chief Information Officer. It collects, organizes, provides for archiving, and disseminates NASA's STI. The NASA STI program provides access to the NASA Aeronautics and Space Database and its public interface, the NASA Technical Reports Server, thus providing one of the largest collections of aeronautical and space science STI in the world. Results are published in both non-NASA channels and by NASA in the NASA STI Report Series, which includes the following report types:

- TECHNICAL PUBLICATION. Reports of completed research or a major significant phase of research that present the results of NASA programs and include extensive data or theoretical analysis. Includes compilations of significant scientific and technical data and information deemed to be of continuing reference value. NASA counterpart of peer-reviewed formal professional papers but has less stringent limitations on manuscript length and extent of graphic presentations.

- TECHNICAL MEMORANDUM. Scientific and technical findings that are preliminary or of specialized interest, e.g., quick release reports, working papers, and bibliographies that contain minimal annotation. Does not contain extensive analysis.

- CONTRACTOR REPORT. Scientific and technical findings by NASA-sponsored contractors and grantees.
- CONFERENCE PUBLICATION. Collected papers from scientific and technical conferences, symposia, seminars, or other meetings sponsored or cosponsored by NASA.

- SPECIAL PUBLICATION. Scientific, technical, or historical information from NASA programs, projects, and missions, often concerned with subjects having substantial public interest.

- TECHNICAL TRANSLATION. Englishlanguage translations of foreign scientific and technical material pertinent to NASA's mission.

Specialized services also include creating custom thesauri, building customized databases, organizing and publishing research results.

For more information about the NASA STI program, see the following:

- Access the NASA STI program home page at http://www.sti.nasa.gov

- E-mail your question to help@sti.nasa.gov

- Fax your question to the NASA STI Information Desk at 443-757-5803

- Phone the NASA STI Information Desk at 443-757-5802

- Write to: STI Information Desk NASA Center for AeroSpace Information 7115 Standard Drive Hanover, MD 21076-1320 
NASA/TM-2013-217902

\section{Limitations of Phased Array Beamforming in Open Rotor Noise Source Imaging}

Csaba Horvath, Edmane Envia, and Gary G. Podboy

Glenn Research Center, Cleveland, Ohio

Prepared for the

19th Aeroacoustics Conference

cosponsored by American Institute of Aeronautics and Astronautics and Confederation of European Aerospace Societies

Berlin, Germany, May 27-29, 2013

National Aeronautics and

Space Administration

Glenn Research Center

Cleveland, Ohio 44135 


\section{Acknowledgments}

This testing and research was funded by the Environmentally Responsible Aviation Project of the NASA Integrated Systems Research Program and the Fixed Wing Project of the NASA Fundamental Aeronautics Program. A portion of the study and the publication of the work was supported by the Hungarian Fund for Science and Research under contract K 83807, and relates to the scientific program of the projects "Development of quality-oriented and harmonized R+D+I strategy and the functional model at BME" and "Talent care and cultivation in the scientific workshops of BME" under the grants TÁMOP-4.2.1/B-09/1/ KMR-2010-0002 and TÁMOP-4.2.2/B-10/1-2010-0009, respectively.

This report is a formal draft or working paper, intended to solicit comments and ideas from a technical peer group.

This report contains preliminary findings, subject to revision as analysis proceeds.

Trade names and trademarks are used in this report for identification only. Their usage does not constitute an official endorsement, either expressed or implied, by the National Aeronautics and Space Administration.

Level of Review: This material has been technically reviewed by technical management.

Available from

NASA Center for Aerospace Information 7115 Standard Drive Hanover, MD 21076-1320
National Technical Information Service 5301 Shawnee Road Alexandria, VA 22312 


\title{
Limitations of Phased Array Beamforming in Open Rotor Noise Source Imaging
}

\author{
Csaba Horvath, Edmane Envia, and Gary G. Podboy \\ National Aeronautics and Space Administration \\ Glenn Research Center \\ Cleveland, Ohio 44135
}

\begin{abstract}
Phased array beamforming results of the F31/A31 historical baseline counter-rotating open rotor blade set were investigated for measurement data taken on the NASA Counter-Rotating Open Rotor Propulsion Rig in the 9- by 15-Foot Low-Speed Wind Tunnel of NASA Glenn Research Center as well as data produced using the LINPROP open rotor tone noise code. The planar microphone array was positioned broadside and parallel to the axis of the open rotor, roughly 2.3 rotor diameters away. The results provide insight as to why the apparent noise sources of the blade passing frequency tones and interaction tones appear at their nominal Mach radii instead of at the actual noise sources, even if those locations are not on the blades. Contour maps corresponding to the sound fields produced by the radiating sound waves, taken from the simulations, are used to illustrate how the interaction patterns of circumferential spinning modes of rotating coherent noise sources interact with the phased array, often giving misleading results, as the apparent sources do not always show where the actual noise sources are located. This suggests that a more sophisticated source model would be required to accurately locate the sources of each tone. The results of this study also have implications with regard to the shielding of open rotor sources by airframe empennages.
\end{abstract}

\section{Nomenclature}

$\begin{array}{ll}B & \text { blade count } \\ \left(f_{\left(n_{1}, n_{2}\right)}\right) & \text { amplitude of oscillation } \\ M_{t} & \text { blade tip Mach number } \\ M_{x} & \text { flight Mach number } \\ n & \text { harmonic indice } \\ \mathrm{X}, \mathrm{Y} & \text { coefficients ranging from 1-3 } \\ z & \text { radial span of the blade } \\ z^{*} & \text { Mach radius } \\ \theta & \text { angle of the viewer to the flight axis }\end{array}$

Subscripts:

A

$\mathrm{F}$

1

2 aft rotor

forward rotor

acoustic harmonic

loading harmonic 


\section{Introduction}

Phased arrays have been effectively applied to many problems where sound source localization was of engineering interest. In the case of propulsion noise, phased arrays have proven to be invaluable diagnostic tools for pinpointing the dominant noise producing components of aircraft engines in both model and full-scale applications (Refs. 1 to 4). An essential element of any phased array analysis is the so-called beamforming step (Refs. 5 and 6), in which the acoustic data acquired by the array is used to reconstruct a visual representation of the noise producing region. Normally the beamforming process assumes that the noise is generated by compact, stationary, incoherent sources and in most applications this does indeed provide source localization as a function of frequency consistent with the underlying physics of the noise generation process. However, this is not always the case. This paper discusses one example where beamforming using these conventional noise source assumptions provides counterintuitive results. The case in point is the source localization for open rotors. In what follows beamforming is applied to phased array data from a model scale open rotor blade set and the results are analyzed to show the shortcoming of conventional beamforming methods. Actual measurement data from wind tunnel measurements and synthesized data from simulations are used to illustrate the point.

\section{Measurement Setup}

Figure 1 shows a photo of the NASA Counter-Rotating Open Rotor Propulsion Rig (ORPR) (Refs. 7 and 8) driving the General Electric (GE) open rotor model, F31/A31, installed in the 9- by 15-Foot LowSpeed Wind Tunnel at the NASA Glenn Research Center. F31/A31 is also known as the historical baseline blade set, since it is representative of the late 1980s aerodynamic design methodology. The open rotor model is roughly $1 / 7^{\text {th }}$ scale, with the forward and aft rotor diameters being 0.652 and $0.630 \mathrm{~m}$, respectively. F31/A31 has 12 forward blades (designated F31) and 10 aft blades (designated A31). Details regarding the blade set can be found in Reference 7 .

The experimental phased array data were acquired using the OptiNAV Array48 system shown in Figure 2. These tests were a part of a larger test campaign investigating open rotor technology from both an aerodynamic as well as aeroacoustic point of view. Details regarding the test setup and examined scenarios of the entire campaign can be found in Reference 7. Figure 2(a) shows the front face of the microphone array, while Figure 2(b) shows the array installed in the sidewall of the wind tunnel. The array consists of 48 flush-mounted microphones fixed in a 1 by $1 \mathrm{~m}$ aluminum plate. A camera is located behind a window at the center of the plate. The camera is used to take a photo of the field of view of the phased array system, and the data processing software superimposes the noise source localization contour

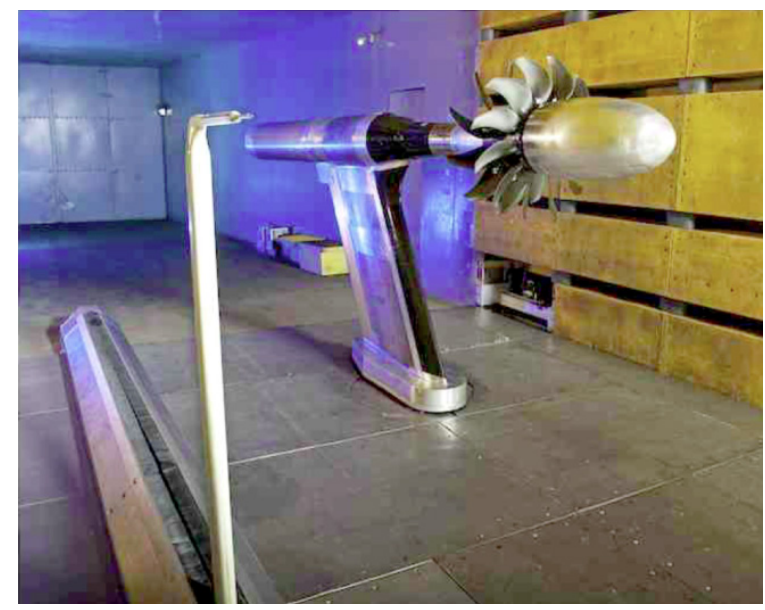

Figure 1.-Photo of the counter-rotating open rotor model installed in the NASA Glenn 9- by 15 -Foot Low-Speed Wind Tunnel. 


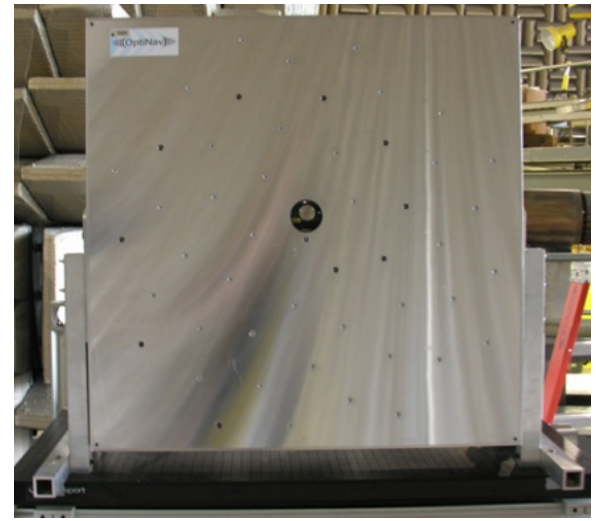

(a)

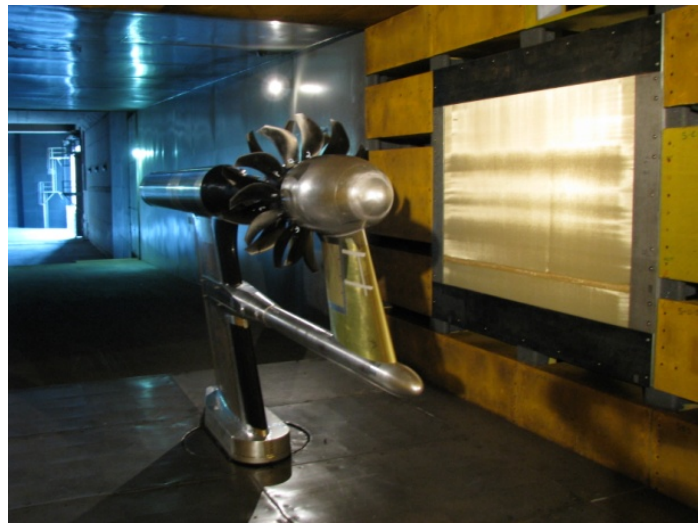

(b)

Figure 2.-(a) Photo showing a close-up view of the Array48 system. (b) Photo showing the array installed in the wall of the of the 9- by 15-Foot Low-Speed Wind Tunnel behind the Kevlar (DuPont, Wilmington, DE) window.

maps on the photo. In order to reduce the boundary layer noise and improve the signal-to-noise ratio, the phased array is recessed into a cavity and a sheet of Kevlar is stretched over the cavity, as previously applied by Jaeger et al. (Ref. 9) This provides a smooth aerodynamic surface for the flow, while allowing acoustic waves to pass through and reach the microphone array. A long sampling time and the removal of the diagonal of the cross spectral matrix were also applied. All three of these techniques improve the dynamic range of the results.

Though many configurations (i.e., blade angle settings, tip speeds, tunnel Mach number, etc.) were examined during the phased array microphone investigations, one configuration suffices to examine the observed phenomena discussed herein. This is the takeoff tip speed with nominal blade angle settings of $40.1^{\circ}$ for the forward rotor and $40.8^{\circ}$ for the aft rotor. The wind tunnel Mach number was 0.2 . The rotors were spinning at an equal (but opposite) mechanical rotational speed of $6590 \mathrm{rpm}$, resulting in a corrected standard day value of $6450 \mathrm{rpm}$. The ORPR was operating at $0^{\circ}$ angle of attack, and was in an isolated configuration (i.e., no pylon or fuselage simulator). Microphone data were acquired for $45 \mathrm{sec}$ at a sampling rate of $96 \mathrm{kHz}$.

\section{Simulation Setup}

The synthesized phased array data were generated using the LINPROP open rotor tone noise code (Ref. 10). The code computes the radiated open rotor tonal sound field from the rotor blade geometries and unsteady aerodynamic blade loading distributions. The unsteady loading distributions were computed using the commercial turbomachinery Computational Fluid Dynamics (CFD) code FINE/Turbo developed by Numeca International. In these CFD investigations, the Nonlinear Harmonic (NLH) methodology (Ref. 11) was applied in order to reduce the computational time required to run the timedependent simulations. The NLH method solves a finite number of the blade passing frequency harmonic components of the time-dependent solution, ignoring all other unsteady components. In the results presented herein, the blade loading mean pressure and the first three harmonics of the Blade Passing Frequency (BPF) of each rotor were solved. The computational domain consisted of one blade passage per blade row, including elements such as the hub and spinner, and extending out to seven tip radii in the radial direction. The resulting 27.1 million grid points were split into multiple blocks and run on parallel processors. The agreement between the measurement data and the simulation results encouraged the further investigation of the sound field based on the CFD results. Further details regarding the CFD simulation methodology and attained results can be found in Reference 10.

LINPROP predicts the sound field from the CFD results using an asymptotic approximation to the Ffowcs Williams-Hawkings (FW-H) equation. In its present form, the code takes into account the loading and the thickness noise sources, but ignores the contribution of the quadrupole source in the FW-H 
equation. In carrying out the asymptotic approximation to the integrals in the FW-H equation, LINPROP does not require the assumption that the observer be in the farfield, making the results valid for any observer position. Owing to the linear nature of the acoustic problem, the contribution of each rotor to the sound field is computed separately and the results are added together. Since the aerodynamic analysis includes mean pressure and perturbation pressures up to the third harmonic, individual rotor tones $\mathrm{nBPF}_{\mathrm{F}}$ and $\mathrm{nBPF}_{\mathrm{A}}$ (arbitrary $\mathrm{n}$ ) and interaction tones up to $3 \mathrm{BPF}_{\mathrm{F}}+3 \mathrm{BPF}_{\mathrm{A}}$ can be computed using LINPROP. Here the subscripts $\mathrm{F}$ and $\mathrm{A}$ refer to the forward and aft rotors, respectively. Further details regarding LINPROP can be found in References 10 and 12.

The time-dependent acoustic field at each Array48 microphone location was synthesized with the LINPROP code for the same blade angle setting, but slightly different corrected rpm, namely 6436, as the measurement data. This slight rpm difference does not affect the results discussed in this paper. It should also be mentioned that LINPROP does not predict the broadband noise, nor does it take into account the blade-to-blade variations experienced in the wind tunnel, be that due to geometric imperfections of the blades, blade angle variations or sensors mounted on the blades.

\section{Processing of the Results}

In acquiring and processing phased array microphone data, our goal is to locate the noise sources that are responsible for the noise radiated from the open rotor. Traditional single microphone measurements provide spectral content and directivity of the sound field, but cannot be used to locate the noise sources.

Beamforming is a process by which a time series of simultaneously attained acoustic data can be processed in order to point the array at a series of examined grid points and determine the source strength distribution (Ref. 6). This technique has proven to be a powerful tool in aerospace investigations, providing a nonintrusive method for acoustic source localization. In this investigation delay-and-sum beamforming in the frequency domain was applied to both the measured and synthesized phased array data. The examined plane used throughout this study was the vertical plane that is parallel to the microphone array and passes through the axis of the ORPR. The cross-spectral matrices created during the processing of the data were constructed using a transform length of 4096, and with $6 \mathrm{~dB}$ subtracted from the measurement results to account for the pressure doubling at the phased array plate surface. The data sets were expressed in shaft orders rather than in Hertz in order to make the tone identification and presentation of the results easier. As stated in the introduction, the beamforming process assumes that the examined noise sources are compact, stationary, and incoherent. In most applications this provides source localization as a function of frequency consistent with the underlying physics of the noise generation process. However, this is not always the case, as will be seen here.

\section{Results}

The recorded microphone array data were processed with the intent of locating the dominant tone noise sources along the span of the forward and aft blades, in order to better understand the noise generation mechanisms of open rotors. Rather surprisingly, the beamforming analysis placed the beamform peak locations for various tones either outboard of the blade tip or inboard of the blade root, within the hub. An example of such results is shown in Figure 3, which depicts the beamforming results for the $\mathrm{BPF}_{\mathrm{F}}+\mathrm{BPF}_{\mathrm{A}}$ interaction tone. In this figure, as in similar figures to be presented later, the top half shows the simulated data using the LINPROP code, and the bottom half shows the corresponding wind tunnel data. The left half of the figure shows the beamform peak Power Spectral Density (PSD) spectrum, while the right half shows the beamforming map for the examined frequency bin, which is indicated by the red asterisk in the PSD plots. Clearly, beamforming has placed the apparent noise source near the axis within the hub instead of somewhere on the blade. Note that both the measured and simulated data exhibit the same behavior. 

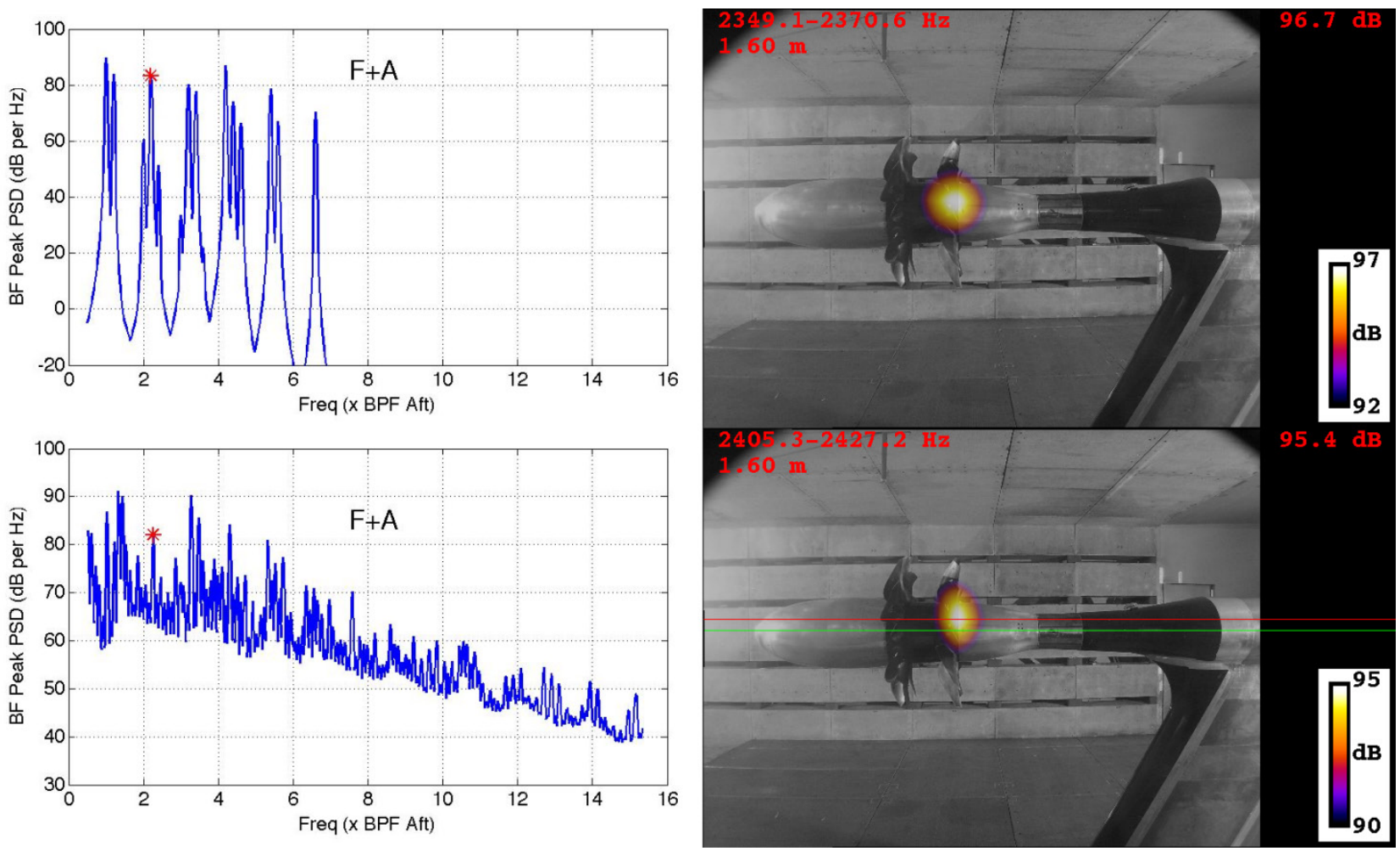

(a)

(b)

Figure 3.-Beamforming results for the $\mathrm{BPF}_{\mathrm{F}}+\mathrm{BPF}_{\mathrm{A}}$ interaction tone. Top row: simulated results. Bottom row: measurement results. (a) Beamform peak PSD. (b) Beamform map.

It should be noted that while the LINPROP predictions indicate that this interaction tone is generated by both the forward and aft rotors, it is generated disproportionately so by the aft rotor. Hence, the location of the peak noise source is correctly identified in the beamform maps as being on the aft rotor.

Surprising results were also observed for other tones. Consider the blade passing tone of the aft rotor, i.e., $\mathrm{BPF}_{\mathrm{A}}$. As can be seen in Figure 4, the apparent noise source is now pinpointed by the beamforming process as being located outboard of the aft blade tip. These results once again stand in contrast to the expectation that the primary source of noise is the blade, and hence the noise sources should appear along the span of the rotors in the beamform maps.

Other beamforming algorithms and deconvolution methods (besides the classical delay and sum method illustrated here) were also tried. The various methods provided similar results, indicating that the location of the apparent noise source is not influenced by the processing method. A comparison of beamform maps generated for the same tone but at different rpm settings also showed similar results. These consistencies suggest an underlying fundamental reason for the surprising results noted above.

The literature regarding counter-rotating propeller acoustics was investigated in an attempt to understand these results. The earliest literature regarding dual-rotating propellers dates back to 1948 , when Hubbard (Ref. 13) investigated the effect of multiple blade rows located on one axis, finding that interference patterns exist, which vary azimuthally, forming lobes. Much later Hanson (Ref. 14) applied his unified theory for noise and performance analysis to counter-rotating propellers. He described how acoustic interference results in spinning modes developing for unsteady loading conditions, gave formulas for determining mode orders (number of lobes around the axis), and discussed how the noise only radiates efficiently if certain criteria are met. He compared the radiation efficiency of counter-rotating open rotors to the cut-off frequency of ducted turbomachinery, as previously described by Tyler and Sofrin (Ref. 15). Hanson explained that certain interaction tones would radiate more efficiently than others. Parry and Crighton (Ref. 16) further investigated the circumferential spinning modes, giving a formula for calculating the radial station at which the radiation efficiency peaks for any given mode. 

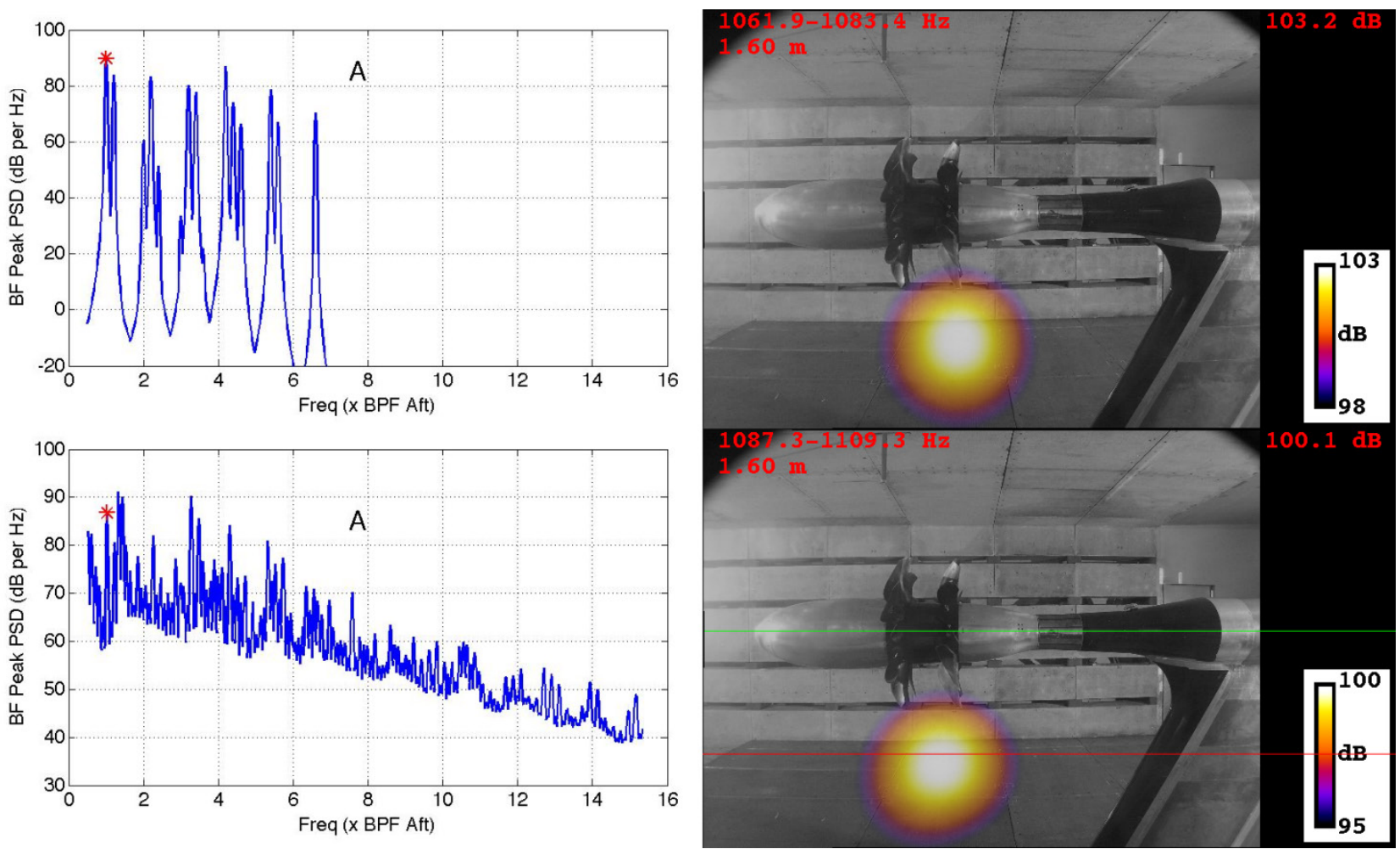

(a)

(b)

Figure 4.-Beamforming results for the $\mathrm{BPF}_{\mathrm{A}}$. Top row: simulated results. Bottom row: measurement results.

(a) Beamform peak PSD. (b) Beamform map.

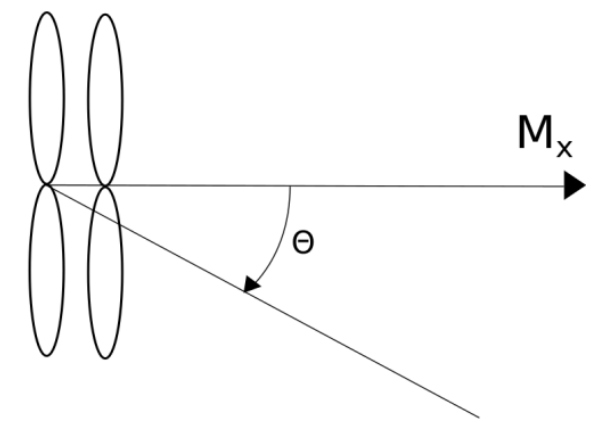

Figure 5.-Diagram depicting the counterrotating open rotor configuration and variables used in calculating the Mach radius.

This radial station, $z^{*}$ (a normalized radius, where $z^{*}=1$ refers to the blade tip), is referred to in the literature as "Mach radius" or "sonic radius" (see Eq. (1)). This name refers to the mode phase speed, the speed at which the lobes of the given mode rotate around the axis, having a Mach number of 1 at $z^{*}$ when examined from the viewpoint of the observer. The report goes on to say that if for any given angle of viewer to flight axis $(\theta)$ (see Fig. 5) there exists a radial section along the blade $(z)$ where $z=z^{*}$ in that direction, then the radiation in direction $\theta$ is dominated by contributions from the vicinity of $z=z^{*}$ rather than the blade tip. A formula is also given for determining the combination frequencies $\left(f_{\left(n_{1}, n_{2}\right)}\right)$ (frequencies at which interaction tones are generated). The results discuss how the interaction tones for instances of harmonic indices ( $n_{1}$ and $n_{2}$ ) having opposite sign (difference tones) have poor radiation efficiencies, since the mode phase speed will be subsonic along the entire span of the blade. In the work 
of Envia (Ref. 10), a different explanation for the poor radiation efficiency was given, showing the relationship between the radiation efficiency and the azimuthal mode number, i.e., the absolute value of the difference between the products of the harmonic indices and the blade counts, Equation (2). $B$ refers to the blade count, with subscripts 1 and 2 referring to the rotor of the acoustic harmonic and loading harmonic, respectively. A connection is shown between the magnitude of the value attained with Equation (2), and the radiation efficiency. Smaller values radiate more efficiently. It can be seen in the comparison that, independently from the location of the Mach radius, the radiation efficiencies of most difference tones are lower than those of sum tones.

$$
\begin{gathered}
z^{*}=\frac{\left(n_{1} B_{1}-n_{2} B_{2}\right)}{\left(n_{1} B_{1} M_{t_{1}}+n_{2} B_{2} M_{t_{2}}\right)} \frac{\left(1-M_{x} \cos \theta\right)}{\sin \theta} \\
\left|n_{1} B_{1}-n_{2} B_{2}\right|
\end{gathered}
$$

The location of the Mach radius (calculated for the angle $\theta=90$ corresponding to a point near the center of the phased array) is shown in Figures 3 and 4 as the red line on the beamform map (the green lines depict the axis of the open rotor). It can be seen that the Mach radius predicts the location of the apparent noise sources quite well. Note, however that the red line does not pass exactly through the center of the beamform peak (i.e., its peak location). This is likely the result of multiple factors. First, in this investigation the phased array, i.e., the observer, is not in the farfield (a stipulation for Equation (1)). Second, the nominal Mach radius is calculated for the center of the array, where $\theta$ is assumed to be $90^{\circ}$. In reality the different microphone locations would correspond to slightly different Mach radii because of the $\theta$ dependence. In examining the errors associated with this simplification, it was found that the errors are negligible in this case, but could be more significant for a larger array of microphones and should be taken into account. Third, there is also an uncertainty associated with the position of the beamform peak, as only a finite number of microphones are used in conducting the investigations. Note that the Mach radius location agrees quite well with the beamforming results for both $z^{*}<1$ and $z^{*}>1$.

Note that the Mach radius corresponding to a given interaction tone is a function of the number of blades and blade tip Mach number $\left(M_{t}\right)$ of each rotor as well as the location of the observer (or, in this case, the phased array) relative to the counter-rotating open rotor. Consequently, Mach radius is a function of the rotor diameter and rotational speed (through the tip Mach number dependence) but not a function of the actual blade shape or blade setting angle. This indicates that the Mach radius corresponding to an interaction tone produced by two different blade sets would be the same, provided both blade sets were examined from the same viewer position and operating at the same flight Mach number $\left(M_{x}\right)$, had the same blade tip Mach numbers and blade counts. It follows that two different blade sets would produce the same noise source localization maps (as a function of Mach radius, but not necessarily amplitude), provided (as is often the case in the experiment, and always the case in the simulation) that the beamform map sources are located at the expected nominal Mach radius.

Contour plots of the wavefronts predicted by the LINPROP code provide insight as to why beamforming locates the sources of coherent rotating noise sources at the nominal Mach radius (an apparent noise source location) instead of at the actual noise source location. These wavefronts are shown in the upper-right corner of Figures 6,7, and 8, as well as in all similar figures appearing in the report. The view depicted is from upstream-looking downstream and shows the pressure contours in the axial plane containing the stacking axis of the aft rotor. The red and blue regions refer to the positions where the sound waves are in phase and interfere to give maximum and minimum values, while the other colors refer to areas where the sound waves are out of phase, giving intermediate values. 

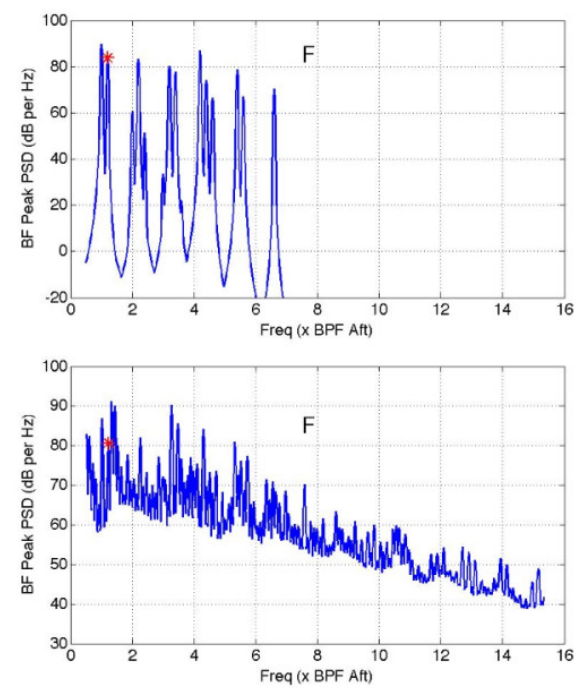

(a)

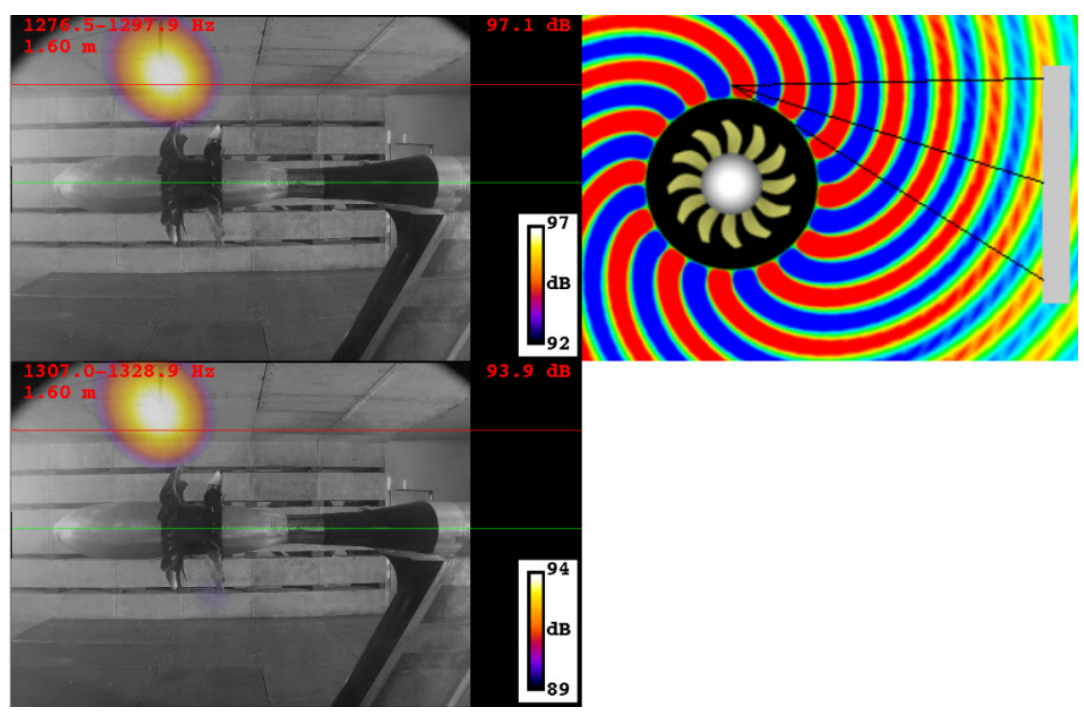

(b)

(c)

Figure 6.-Beamforming results for the $\mathrm{BPF}_{\mathrm{F}}$. Top row: simulated results. Bottom row: measurement results. Left side: Beamform peak PSD. Middle: Beamform map. Right side: Contour map of the sound field.
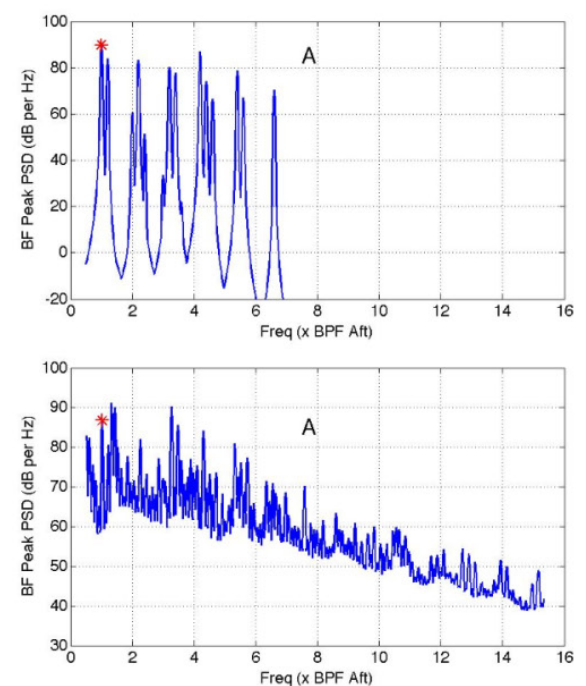

(a)

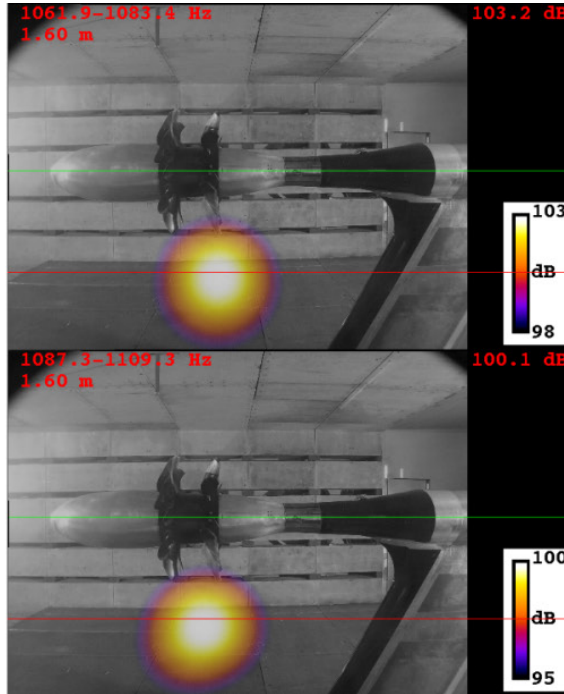

(b)

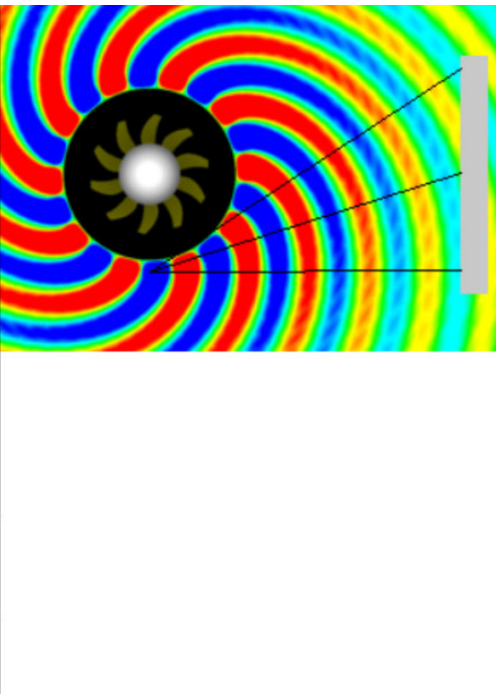

(c)

Figure 7.-Beamforming results for the $\mathrm{BPF}_{\mathrm{A}}$. Top row: simulated results. Bottom row: measurement results.

Left side: Beamform peak PSD. Middle: Beamform map. Right side: Contour map of the sound field. 

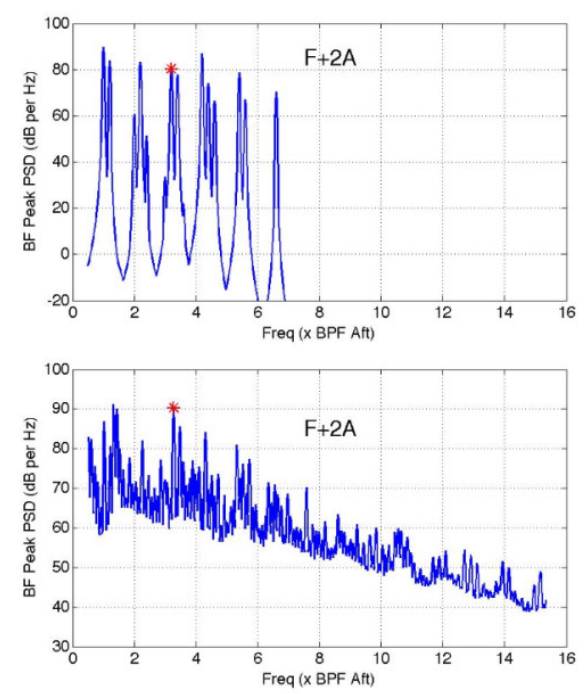

(a)

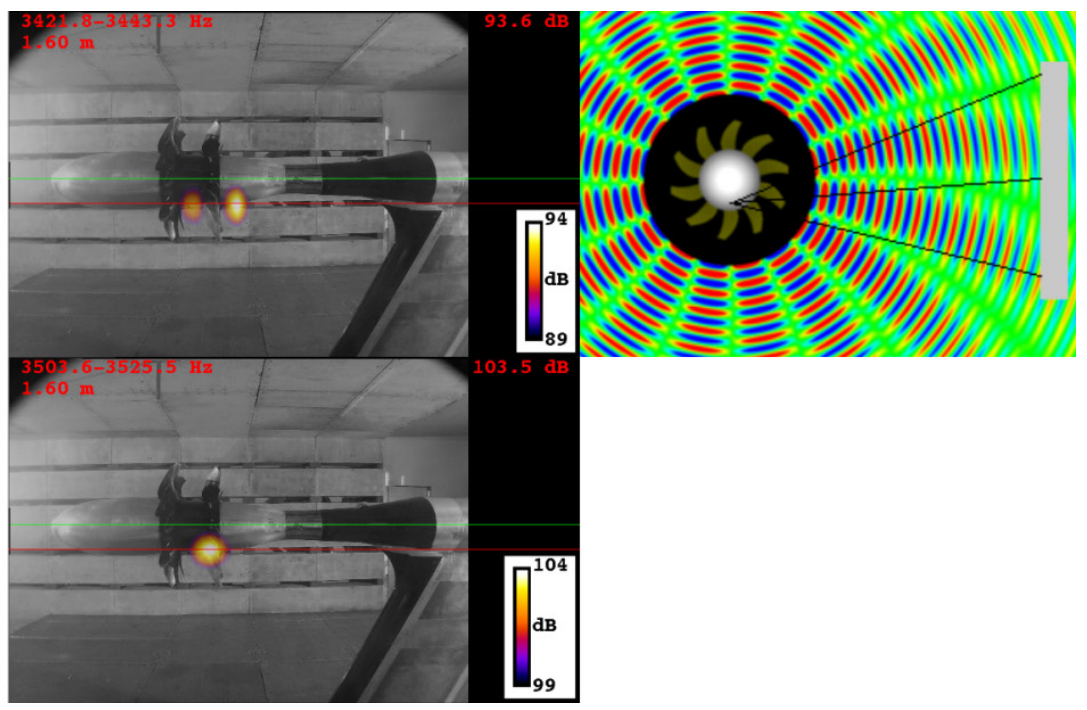

(b)

(c)

Figure 8.-Beamforming results for the $\mathrm{BPF}_{\mathrm{A}}+2 \mathrm{BPF} \mathrm{F}_{\mathrm{A}}$ Top row: simulated results. Bottom row: measurement results. Left side: Beamform peak PSD. Middle: Beamform map. Right side: Contour map of the sound field.

The $\mathrm{BPF}_{\mathrm{F}}$ wavefront exhibits a 12 lobe pattern (corresponding to the 12 rotor blades, Fig. 6) that rotates clockwise about the rig axis in the same direction as the front rotor. The wavefront for $\mathrm{BPF}_{\mathrm{A}}$ (Fig. 7) exhibits a 10 lobe pattern corresponding to the 10 aft blades and rotates counter-clockwise about the rig axis in the same direction as the aft rotor blades. The wavefront for the $\mathrm{BPF}_{\mathrm{F}}+2 \mathrm{BPF}_{\mathrm{A}}$ tone (Fig. 8) has an 8 lobe pattern corresponding to the azimuthal mode number of this interaction tone as given by Equation (2). The pattern shown in Figure 8 is a superposition of the contribution to this interaction tone from both rotors, though for this case it is dominated by the contribution from the aft rotor and hence it rotates in the same direction as the aft rotor.

The propagation of the sound waves from coherent noise sources away from the model coupled with the rotation of the noise sources about an axis produces the spiral patterns depicted in these contour plots, as the sound waves add up constructively or destructively. The grey rectangle superimposed at the right in the contour plots depicts the location of the Array48 phased array system relative to the open rotor. The phased array beamforming process attempts to locate the source of the sound waves intercepted by the array microphones. In essence, the process is akin to determining the normal to the wavefronts at each microphone location and tracing these normals back to the source region. Their crossing point represents the estimated apparent noise source location. Three such normals spanning the vertical span of the array are shown in Figures 6, 7, and 8. These crossing points do in fact converge at the source location identified by the beamforming process in all cases. These clearly illustrate how the beamforming process can place the noise at an apparent (as opposed to real) noise source location because of the spiraling nature of the wavefront propagating away from the open rotor. The fact that the virtual source locations are the same for most of the measured tones indicates that the same sorts of spiral wavefronts are also generated in actual experiments. As was stated earlier, the theory in Parry and Crighton (Ref. 16) states that the noise sources will radiate most efficiently from the Mach radius for supersonic tip speeds, i.e., if the Mach radius is located on the blades. As can be seen in the results, the rotating coherent noise sources always radiate most efficiently from the nominal Mach radius, and give the apparent noise sources as being located at these positions.

It should be noted that, while the apparent noise source locations for the actual and simulated data agree well in most cases, this is not a general result. There are cases for which the experimental beamform maps do not line up with the expected nominal Mach radius. Figure 9 shows the case corresponding to $2 \mathrm{BPF}_{\mathrm{F}}$. The simulation results line up with the corresponding nominal Mach radius as would be expected, while the measurement results show the sources in an entirely different location. 

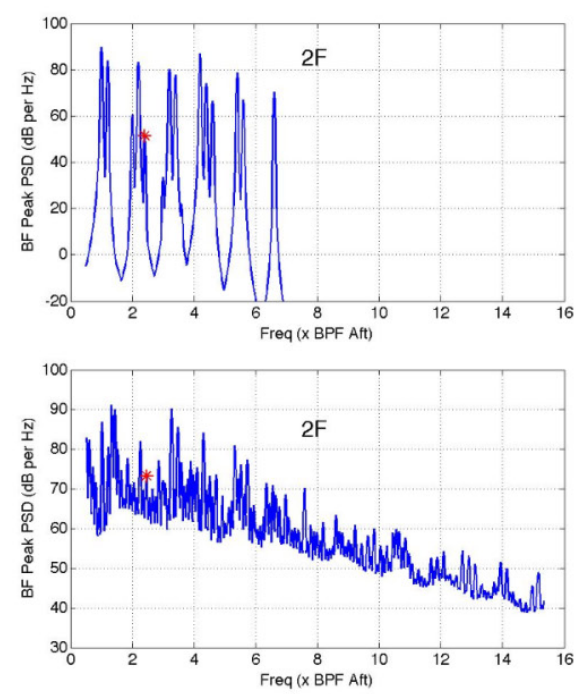

(a)

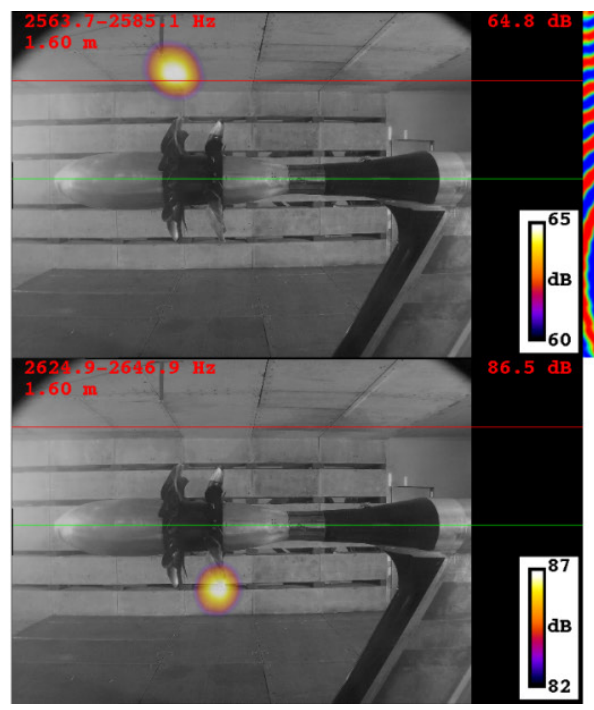

(b)

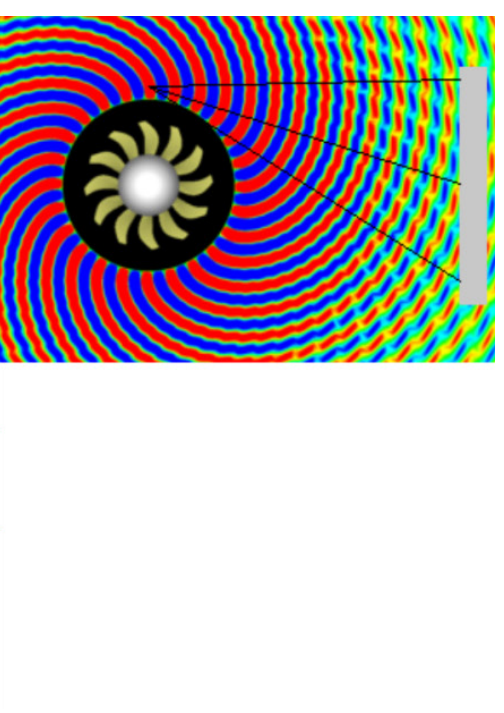

(c)

Figure 9.-Beamforming results for the $2 \mathrm{BPF}_{\mathrm{F}}$. Top row: simulated results. Bottom row: measurement results. Left side: Beamform peak PSD. Middle: Beamform map. Right side: Contour map of the sound field.

Each nominal Mach radius location corresponds to a specific tone. Therefore, in calculating the nominal Mach radius corresponding to a given frequency bin, the first step is to determine the tone which is expected to dominate the noise source map. In Figure 9, the $2 \mathrm{BPF}_{\mathrm{F}}$ tone was expected to be the dominant noise source in the map, and the red line corresponds to the Mach radius for this tone. The beamform maps provided in Figure 9 show the noise coming from the Mach radius corresponding to $2 \mathrm{BPF}_{\mathrm{F}}$ in the simulation but not the experiment. The simulation predicts tone noise resulting from the loading and thickness noise produced by identical blades. For cases such as this where the experimental results do not line up with the expected Mach radius it appears that some source other than the loading and thickness noise produced by identical blades (i.e., those sources included in the simulation) controls the amplitude of the tone. One such source would be blade-to-blade variations. These could produce shaft order tones which fall into the same frequency bin, and are numerous, even if the difference tones are not taken into consideration due to their poor radiation efficiency (Refs. 10 and 16). For the case examined here, many shaft order tones would fall into the same frequency bin as $2 \mathrm{BPF}_{\mathrm{F}}$, including $23 / 12 \mathrm{BPF}_{\mathrm{F}}+1$ / $10 \mathrm{BPF}_{\mathrm{A}}, 22 / 12 \mathrm{BPF}_{\mathrm{F}}+2 / 10 \mathrm{BPF}_{\mathrm{A}}, \ldots 2 / 12 \mathrm{BPF}_{\mathrm{F}}+22 / 10 \mathrm{BPF}_{\mathrm{A}}, 1 / 12 \mathrm{BPF}_{\mathrm{F}}+23 / 10 \mathrm{BPF}_{\mathrm{A}}$ and $24 / 10 \mathrm{BPF}_{\mathrm{A}}$. Another possible source would be quadrupole noise, which is not included in the simulated results.

The Mach radius concept and the spiral wavefronts discussed above apply to rotating sources. When the principal source is not rotating, such as would be the case for a pylon wake being chopped by a downstream rotor, the Mach radius concept does not apply. As an example, consider the situation depicted in Figure 10. The presence of the upstream pylon augments the front rotor content at the $\mathrm{BPF}_{\mathrm{F}}, 2 \mathrm{BPF}_{\mathrm{F}}, 3 \mathrm{BPF}_{\mathrm{F}}$, etc. Unlike the isolated rotor, in this case the pylon-rotor interaction source is stationary. As such, the associated wavefronts do not spiral like they do when the sound field is produced by the rotating blades. In this case the beamforming process correctly images the noise source onto the blade itself.

The sound field of a counter-rotating open rotor is not composed of only tonal components. The simulations, as can be seen in the PSD spectra, do not investigate the broadband noise sources. The measurement results on the other hand show that the broadband noise is significant, with many interaction tones, especially those at higher frequencies, being buried in the broadband. This investigation does not deal with the broadband noise in greater detail, but it is assumed that since noise sources which appear at nominal Mach radii should be rotating and coherent in order to form the rotating lobes depicted in the figures, the broadband noise will not appear at a nominal Mach radius. 


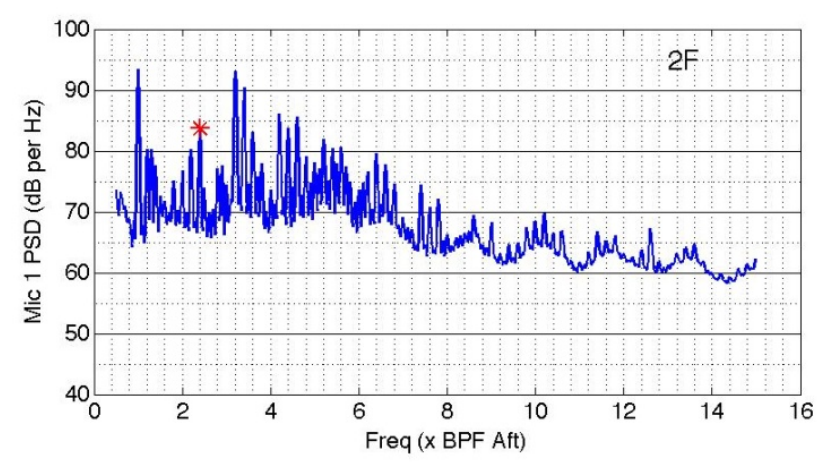

(a)

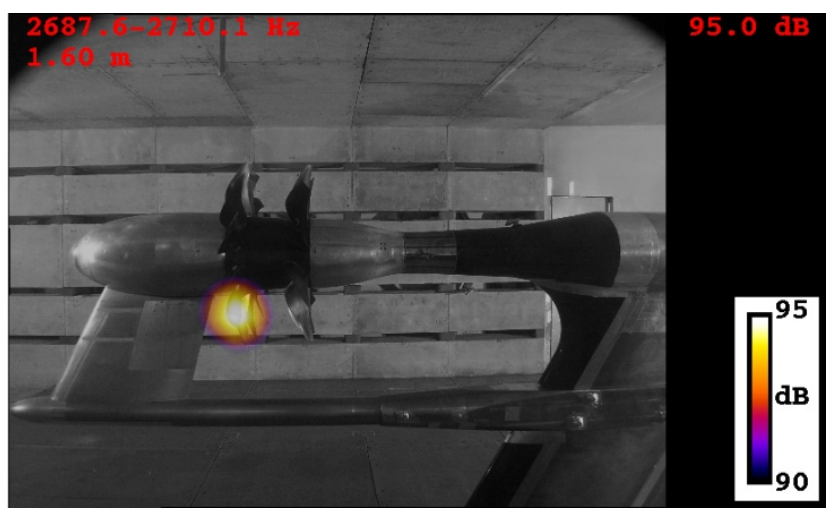

(b)

Figure 10.-2BPF $\mathrm{F}_{\mathrm{F}}$ beamform results of the measurement of the takeoff blade angle settings at Ma 0.22 with a pylon. (a) Beamform peak PSD. (b) Beamform map.

\section{Conclusions}

The application of the beamforming analysis to open rotors was examined. It was shown that the conventional beamforming techniques place the apparent sources of noise for certain tones off the blade (outboard of the tip or inboard of the root). These surprising results were explained by appealing to the concept of Mach radius and further elucidated by examining the predicted spiraling wavefronts emanating from the open rotor. The Mach radius is a theoretical construct indicating the location of the maximum radiation efficiency of rotating blades. A more intuitive picture emerges by tracing the normal to the wavefronts at the location of the phased array back to the source region. Together, these theoretical devices provide a robust explanation of the nature of the beamforming maps. It was further shown that the apparent source location corresponding to a rotating coherent noise source will always be at the Mach radius regardless of whether the Mach radius is smaller or larger than the blade tip radius, when the blades in each rotor are assumed identical and the broadband noise is not considered, as is the case in theoretical simulations. For the real blades, beamforming may place the apparent noise source of a tone at a location other than the Mach radius due to variations in the blade geometry, or due to sources, such as quadrupole noise sources, which are not accounted for in the simulations, or due to the tonal components being buried in the broadband.

The beamform maps of rotating coherent noise sources were understood. This information can be very useful in further examining counter-rotating open rotors, as well as other rotating coherent noise sources. A more sophisticated beamform model, based on these findings, should be able to provide a means for locating the real noise sources of rotating coherent noise sources.

Finally, the beamforming results could serve as a guide for installing the open rotor engines on the airframe in such a way as to maximize noise shielding by taking into account the virtual source locations. Without the beamforming results (which tend to validate the Mach radius concept), one may design the shield (say the vertical tails in a U-Tail arrangement) to only block the physical extent of the rotor. This may miss an apparent noise source outboard of the blade and thus reduce the effectiveness of the shield.

\section{References}

1. Storms, B.L., Ross, J.C., Horne, W.C., Hayes, J.A., Dougherty, R.P., Underbrink, J.R., Scharpf, D.F., and Moriarty, P.J., "An Aeroacoustic Study of an Unswept Wing With a Three-Dimensional High-Lift System,” NASA TM-1998-11222, February, 1998.

2. Brusniak, L., Underbrink, J.R., and Stoker, R.W., "Acoustic Imaging of Aircraft Noise Sources Using Large Aperture Phased Arrays," $12^{\text {th }}$ AIAA/CEAS Aeroacoustics Conference, AIAA-20062715, 2006. 
3. Podboy, G.G., Bridges, J.E., and Henderson, B.S., "Phased Array Noise Source Localization Measurements of an F404 Nozzle Plume at Both Full and Model Scale," ASME Turbo Expo 2010:

Power for Land, Sea and Air, GT2010-22601, 2010.

4. Podboy, G.G., and Horvath, Cs., "Phased Array Noise Source Localization Measurements made on a Williams International FJ44 Engine," $15^{\text {th }}$ AIAA/CEAS Aeroacoustics Conference $\left(30^{\text {th }}\right.$ AIAA Aeroacoustics Conference), AIAA-2009-3183, 2009.

5. Sijtsma, P., "Acoustic Beamforming for the Ranking of Aircraft Noise,” NLR-TP-2012-137, 2012.

6. Mueller, T.J., Aeroacoustic Measurements, Springer-Verlag, Berlin, 2002, Chaps. 2.

7. Van Zante, D.E., Gazzaniga, J.A., Elliott, D.M., and Woodward, R.P., "An Open Rotor Test Case: F31/A31 Historical Baseline Blade Set," XX International Symposium on Air Breathing Engines 2011, ISABE-2011-1310, 2011.

8. Woodward, R.P., Hall, D.G., Podboy, G.G., and Jeraki, R.J., "Takeoff/Approach Noise for a Model Counterrotation Propeller With a Forward-Swept Upstream Rotor," $31^{\text {st }}$ Aerospace Science Meeting \& Exhibition, AIAA-93-0596, 1993.

9. Jaeger, S.M., Horne, W.C., and Allen, C.S., "Effect of Surface Treatment on Array Microphone Self-Noise," $6^{\text {th }}$ AIAA/CEAS Aeroacoustics Conference, AIAA-2000-1937, 2000.

10. Envia, E., "Open Rotor Aeroacoustic Modelling," Conference on Modelling Fluid Flow, edited by. Vad, J., Budapest, 2012.

11. He, L., and Ning, W., "Efficient Approach for Analysis of Unsteady Viscous Flows in Turbomachines," AIAA Journal, Vol. 36, No. 11, 1998, pp. 2005-2011.

12. Envia, E., "Asymptotic Theory of Supersonic Propeller Noise," AIAA Journal, Vol. 32, No. 2, 1994, pp. 239-246.

13. Hubbard, H.H., "Sound From Dual-Rotating and Multiple Single-Rotating Propellers," NACA TN no. $1654,1948$.

14. Hanson, D.B., "Noise of Counter-Rotation Propellers," AIAA/NASA $9^{\text {th }}$ Aeroacoustics Conference, AIAA-84-2305, 1984.

15. Tyler, J.M., and Sofrin, T.G., "Axial Flow Compressor Noise Studies,” SAE J., Vol. 70, 1962, pp. 309-332.

16. Parry, A.B., and Crighton, D.G., "Prediction of Counter-Rotation Propeller Noise," $12^{\text {th }}$ AIAA Aeroacoustics Conference, AIAA-89-1141, 1989. 



\begin{tabular}{|c|c|c|}
\hline \multicolumn{2}{|c|}{ REPORT DOCUMENTATION PAGE } & $\begin{array}{l}\text { Form Approved } \\
\text { OMB No. 0704-0188 }\end{array}$ \\
\hline \multicolumn{3}{|c|}{ 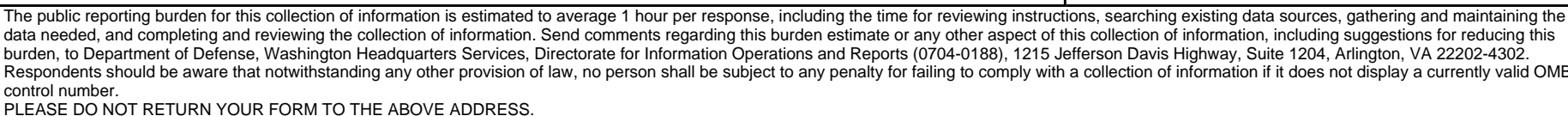 } \\
\hline $\begin{array}{l}\text { 1. REPORT DATE (DD-MM-YYYY) } \\
01-08-2013\end{array}$ & $\begin{array}{l}\text { 2. REPORT TYPE } \\
\text { Technical Memorandum }\end{array}$ & 3. DATES COVERED (From - To) \\
\hline \multirow{3}{*}{\multicolumn{2}{|c|}{$\begin{array}{l}\text { 4. TITLE AND SUBTITLE } \\
\text { Limitations of Phased Array Beamforming in Open Rotor Noise So }\end{array}$}} & 5a. CONTRACT NUMBER \\
\hline & & 5b. GRANT NUMBER \\
\hline & & 5c. PROGRAM ELEMENT NUMBER \\
\hline \multirow{3}{*}{\multicolumn{2}{|c|}{$\begin{array}{l}\text { 6. AUTHOR(S) } \\
\text { Horvath, Csaba; Envia, Edmane; Podboy, Gary, G. }\end{array}$}} & 5d. PROJECT NUMBER \\
\hline & & 5e. TASK NUMBER \\
\hline & & $\begin{array}{l}\text { 5f. WORK UNIT NUMBER } \\
\text { WBS 699959.02.09.03.05 }\end{array}$ \\
\hline \multicolumn{2}{|c|}{$\begin{array}{l}\text { 7. PERFORMING ORGANIZATION NAME(S) AND ADDRESS(ES) } \\
\text { National Aeronautics and Space Administration } \\
\text { John H. Glenn Research Center at Lewis Field } \\
\text { Cleveland, Ohio 44135-3191 }\end{array}$} & $\begin{array}{l}\text { 8. PERFORMING ORGANIZATION } \\
\text { REPORT NUMBER } \\
\text { E-18714 }\end{array}$ \\
\hline \multirow{2}{*}{\multicolumn{2}{|c|}{$\begin{array}{l}\text { 9. SPONSORING/MONITORING AGENCY NAME(S) AND ADDRESS(ES) } \\
\text { National Aeronautics and Space Administration } \\
\text { Washington, DC 20546-0001 }\end{array}$}} & $\begin{array}{l}\text { 10. SPONSORING/MONITOR'S } \\
\text { ACRONYM(S) } \\
\text { NASA }\end{array}$ \\
\hline & & $\begin{array}{l}\text { 11. SPONSORING/MONITORING } \\
\text { REPORT NUMBER } \\
\text { NASA/TM-2013-217902 }\end{array}$ \\
\hline \multicolumn{3}{|c|}{$\begin{array}{l}\text { 12. DISTRIBUTIONIAVAILABILITY STATEMENT } \\
\text { Unclassified-Unlimited } \\
\text { Subject Categories: } 07 \text { and } 71 \\
\text { Available electronically at http://www.sti.nasa.gov } \\
\text { This publication is available from the NASA Center for AeroSpace Information, 443-757-5802 }\end{array}$} \\
\hline
\end{tabular}

\section{SUPPLEMENTARY NOTES}

\section{ABSTRACT}

Phased array beamforming results of the F31/A31 historical baseline counter-rotating open rotor blade set were investigated for measurement data taken on the NASA Counter-Rotating Open Rotor Propulsion Rig in the 9- by 15-Foot Low-Speed Wind Tunnel of NASA Glenn Research Center as well as data produced using the LINPROP open rotor tone noise code. The planar microphone array was positioned broadside and parallel to the axis of the open rotor, roughly 2.3 rotor diameters away. The results provide insight as to why the apparent noise sources of the blade passing frequency tones and interaction tones appear at their nominal Mach radii instead of at the actual noise sources, even if those locations are not on the blades. Contour maps corresponding to the sound fields produced by the radiating sound waves, taken from the simulations, are used to illustrate how the interaction patterns of circumferential spinning modes of rotating coherent noise sources interact with the phased array, often giving misleading results, as the apparent sources do not always show where the actual noise sources are located. This suggests that a more sophisticated source model would be required to accurately locate the sources of each tone. The results of this study also have implications with regard to the shielding of open rotor sources by airframe empennages.

\section{SUBJECT TERMS}

Acoustics; Phased arrays; Open rotor; Counter-rotating; Noise source location

\begin{tabular}{|l|l|l|l|c|l|}
\hline \multicolumn{2}{|l|}{ 16. SECURITY CLASSIFICATION OF: } & $\begin{array}{l}\text { 17. LIMITATION OF } \\
\text { ABSTRACT }\end{array}$ & $\begin{array}{l}\text { 18. NUMBER } \\
\text { OF } \\
\text { PAGES }\end{array}$ & $\begin{array}{l}\text { 19a. NAME OF RESPONSIBLE PERSON } \\
\text { STI Help Desk (email:help@sti.nasa.gov) }\end{array}$ \\
\cline { 1 - 2 } $\begin{array}{l}\text { a. REPORT } \\
\text { U }\end{array}$ & $\begin{array}{l}\text { b. ABSTRACT } \\
\text { U }\end{array}$ & $\begin{array}{l}\text { c. THIS } \\
\text { PAGE } \\
\text { U }\end{array}$ & UU & 20 & $\begin{array}{l}\text { 19b. TELEPHONE NUMBER (include area code) } \\
\text { 4 }\end{array}$ \\
& & & \\
\hline
\end{tabular}



